\title{
Efeito-vizinhança e o desempenho escolar: o caso dos estudantes da rede pública de ensino da cidade do Recife
}

Neighborhood effect and school performance: the case of students from public schools in the city of Recife

\author{
Julia Rocha Araujo (1) \\ Raul da Mota Silveira Neto (2) \\ (1) Universidade Federal do Rio Grande do Norte \\ (2) Universidade Federal de Pernambuco
}

\section{Resumo}

Este artigo tem como objetivo analisar a influência da vizinhança sobre o desempenho escolar dos alunos da rede pública de ensino do Recife. Especificamente, o trabalho investiga empiricamente a existência de uma relação entre o desempenho do aluno e as características de sua vizinhança e os mecanismos pelos quais atua essa influência. Para tanto, utiliza-se a base de dados da Fundaj (2013) para construir, de forma pioneira no Brasil, as variáveis de vizinhança dos alunos da cidade considerando pequenas escalas geográficas. Os resultados dos exercícios econométricos indicam que os alunos residentes em uma vizinhança mais privilegiada tendem a apresentar, em média, melhor desempenho em matemática. $\mathrm{Na}$ análise que considera a composição dos pares de vizinhança, os resultados sugerem que a proporção de repetentes influenciaria o desempenho de matemática.

\section{Palavras-chave}

desempenho escolar, efeito vizinhança, segregação residencial.

Códigos JEL $124, R 23$.

JEL Codes I24, R23. 


\section{Introdução}

A associação entre a vizinhança e a trajetória individual tem sido preocupação de diversos pesquisadores desde o trabalho seminal de Wilson (1970). Em termos gerais, os trabalhos argumentam que as crianças pobres que vivem nas áreas mais precárias teriam maior dificuldade em sair da pobreza do que outras com características socioeconômicas semelhantes que vivem em áreas mais abastadas, porque elas tendem a ter pouco contato com outros colegas com perfis socioeconômicos diferentes, são menos expostas aos exemplos de sucesso profissional via escolaridade e possuem menor acesso às escolas de boa qualidade (Wilson, 1987; Jencks; Mayer, 1990).

Dentro desse contexto, os estudos têm sugerido três mecanismos pelos quais a vizinhança afetaria o desempenho escolar: a) influência dos colegas, quando uma criança tende a imitar o comportamento de seus colegas; b) influência dos adultos, quando as crianças aprendem sobre quais comportamentos são considerados adequados por meio da interação com os adultos de sua vizinhança, de tal modo que os resultados obtidos pelos adultos em suas vidas profissionais serviriam de motivação para os mais novos (Jencks; Mayer, 1990; Ainsworth, 2002; Ribeiro; Koslinski, 2009); c) influência do contexto da vizinhança (modelo institucional) que analisa como a qualidade do serviço de infraestrutura de uma vizinhança ${ }^{1}$ pode afetar os resultados individuais.

Os estudos empíricos internacionais não são consensuais quanto ao efeito do local de moradia sobre o desempenho acadêmico. Por exemplo, enquanto os trabalhos de Crane (1991) e Goux e Maurin (2007) apontam efeitos significativos dos colegas vizinhos sobre a evasão escolar, repetência e atraso escolar, respectivamente. Gibbons et al. (2013) não encontraram evidências significativas da influência das características da vizinhança sobre as notas dos alunos.

Nem mesmo as pesquisas baseadas em experimentos, como o programa Moving to Opportunity (MTO), que atenua o problema de autosseleção, são unânimes quanto ao impacto da vizinhança. Ludwig et al. (2001), por exemplo, encontraram efeitos positivos sobre o desempenho de leitura e

1 A qualidade da escola, por exemplo, pode variar de acordo com o contexto da vizinhança, já que as vizinhanças mais ricas têm mais facilidade em atrair e reter professores mais experientes e qualificados (Jencks; Mayer, 1990; Ainsworth, 2002; Ribeiro; Koslinski, 2009). 
matemática das crianças pertencentes a famílias beneficiadas com o subsídio habitacional em Baltimore. Já Sanbonmatsu et al. (2006), considerando todas as cidades contempladas pelo programa MTO, não verificaram efeito significativo sobre a proficiência de leitura e matemática dos estudantes.

Uma possível explicação para a falta de consenso pode estar associada à forma como a vizinhança é definida, bem como à adoção de diferentes estratégias empíricas utilizadas para mensurar o impacto da vizinhança sobre o desempenho dos alunos (Durlauf, 2004).

No Brasil, embora na última década tenham aumentado os esforços para compreender os determinantes das desigualdades educacionais (Menezes-Filho, 2007; Menezes-Filho; Ribeiro, 2009; Esteves de Moraes; Beluzzo, 2014), pesquisas sobre a relação entre vizinhança e os resultados escolares ainda são raras. Os poucos estudos são voltados principalmente para as capitais do Sudeste, nenhum deles com informações sobre a localização da residência do aluno.

Torres et al. (2004) argumentaram que a segregação espacial tem reflexos negativos sobre os resultados escolares das crianças que residem nas favelas de São Paulo, sendo estas penalizadas pelo seu baixo nível socioeconômico, por não conviverem com colegas de nível mais elevado e pela interação entre seu baixo nível socioeconômico e o meio em que elas vivem. Já Vasconcellos e Rocha (2006) e Alves et al. (2008) investigaram a associação entre morar na favela no Rio de Janeiro e os resultados escolares. $O$ primeiro estudo verificou que a probabilidade de um jovem residente em favela frequentar a escola aumenta se o grupo desse jovem frequentar a escola. $\bigcirc$ segundo encontrou evidências de que existe uma influência negativa do local de moradia sobre a distorção idade-série.

Ribeiro e Koslinski (2009) investigaram a influência do nível socioeconômico da vizinhança das escolas do Rio de Janeiro na proficiência escolar. Diante da indisponibilidade de dados georreferenciados dos alunos, os autores assumiram que a vizinhança das escolas seria uma boa proxy da vizinhança dos alunos a partir do argumento de que os estudantes estudam próximos às suas residências. Seus resultados indicam uma associação direta entre as características do entorno escolar e o desempenho.

Com objetivo semelhante, Soares et al. (2008) focaram na influência do nível socioeconômico da vizinhança da escola sobre o desempenho dos alunos em Belo Horizonte, não encontrando evidências significativas. Possivelmente, os efeitos do bairro podem ser totalmente absorvidos pela 
composição social das escolas. A influência do ambiente escolar sobre o comportamento dos estudantes é reforçada por Becker e Kassouf (2016), cujos resultados sugerem que a probabilidade de a escola registrar pelo menos um ato agressivo de um aluno é maior quanto maior for o número de ocorrências de crimes contra o patrimônio, contra a pessoa, tráfico de drogas ou atuação de gangues nas unidades escolares.

O presente estudo pretende investigar empiricamente a existência da relação entre o desempenho escolar e as características de vizinhança na Cidade do Recife. Para tanto, utiliza-se uma ampla base de dados disponibilizada pela Fundação Joaquim Nabuco (Fundaj) (2013), que reúne informações dos alunos do sexto ano das escolas públicas. Trata-se de um banco de dados banco único e particularmente útil para a pesquisa, onde se destacam as informações a respeito dos endereços das residências e das escolas dos alunos, dos critérios de escolha da escola e do local de moradia por parte dos responsáveis. Além disso, o desempenho de matemática de um aluno foi mensurado em dois momentos distintos no tempo, no início e no final do ano. Argumenta-se que a primeira nota seja capaz de captar as características não observáveis dos alunos que não variam no tempo e que se correlacionam com o desempenho escolar (Ding; Lehrer, 2007, Raposo et al., 2015).

Esta pesquisa, então, distingue-se dos demais estudos nacionais por identificar a localização exata do aluno e por utilizar um rico conjunto de variáveis de controle do âmbito familiar e escolar. A partir dos endereços dos alunos foram identificadas as características da vizinhança, baseadas em pequenas escalas geográficas (setor censitário, raios de 250 e 500 metros). A análise da associação entre o desempenho escolar e a organização territorial de Recife é feita por meio de um índice representativo da qualidade da vizinhança, que incorpora tanto o acesso à infraestrutura quanto os atributos sociodemográficos. Já a análise da influência dos pares da vizinhança é desenvolvida a partir do percentual de deficientes, homens, beneficiários do Bolsa Família e repetentes (Gibbons et al. 2013).

Os resultados indicam que o desempenho de matemática dos alunos do sexto ano da rede pública de ensino de Recife está associado positivamente à organização socioespacial. Os alunos que moram em vizinhanças mais privilegiadas tendem a apresentar maior desempenho em matemática, na média. Já os resultados dos pares de vizinhanças indicam que apenas a proporção de repetentes se mostrou relevante, e somente para as menores 
vizinhanças. Em média, os estudantes que moram em vizinhanças com maiores proporções de repetentes tendem a apresentar menor desempenho em matemática.

Embora a estratégia empírica adotada não possa garantir necessariamente a obtenção de uma relação causal entre vizinhança e desempenho escolar, acredita-se que este trabalho contribui para o conhecimento disponível na literatura brasileira sobre a questão. Ainda que se reconheçam limitações quanto à validade externa da pesquisa, uma vez que trata unicamente do caso da Cidade do Recife, o fato de tratar-se de uma capital importante do Nordeste do Brasil aumenta as possibilidades de validade externa dos resultados, se não para demais capitais do país, pelo menos para as grandes cidades dessa região.

Além desta introdução, este estudo está organizado em mais quatro seções. A segunda seção realiza uma análise descritiva da organização espacial das escolas e dos alunos que estudam em Recife. A terceira seção apresenta e discute a estratégia empírica e a base de dados adotada. Os resultados encontrados das estimações econométricas estão apresentados na quarta seção. Na última seção, são oferecidas as considerações finais.

\section{Características socioespaciais do Recife}

A Cidade do Recife é caracterizada por ser macrossegregada (Oliveira; Silveira Neto, 2016) e por possuir elevada persistência intergeracional dos níveis educacionais (Gonçalves; Silveira Neto, 2013). A Figura 1 ilustra a distribuição espacial dos grupos extremos de renda ao longo do tecido urbano: o painel (a) indica a concentração dos mais pobres ${ }^{2}$, ao passo que o painel (b) identifica a concentração dos mais ricos ${ }^{3}$. O mapa será mais escuro quanto mais homogêneas forem as áreas.

Conforme Oliveira e Silveira Neto (2016), os mais ricos estão concentrados em dois pontos específicos e isolados entre si: ao sul, próximos à praia de Boa Viagem; e ao norte, próximos ao Rio Capibaribe e ao centro econômico e político-administrativo (em amarelo). Os mais pobres, por

2 Domicílios que possuem renda domiciliar per capita menor ou igual a 1/2 salário mínimo em 2010.

3 Domicílios que possuem renda domiciliar per capita maior ou igual a cinco salários mínimos em 2010. 
sua vez, são mais dispersos no território recifense, estando presentes tanto nas áreas vizinhas ao centro quanto nas extremidades da cidade.

Figura 1 Localização dos mais ricos e dos mais pobres do Recife em 2010

a) Localização dos mais pobres

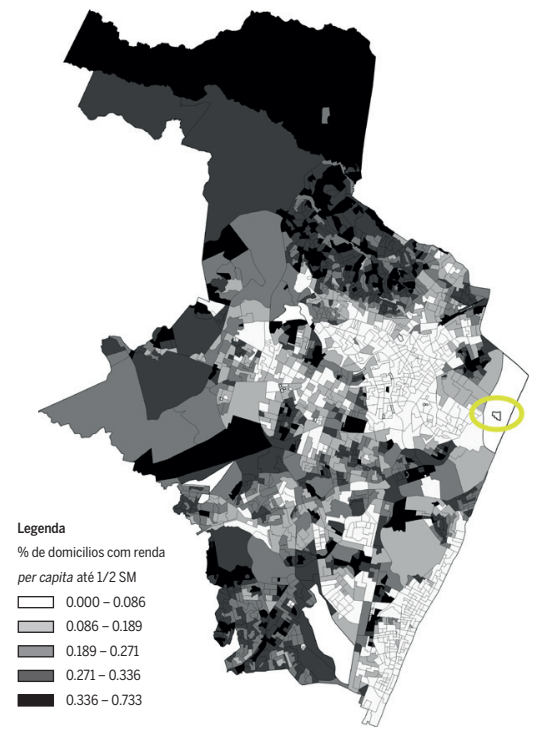

b) Localização dos mais ricos

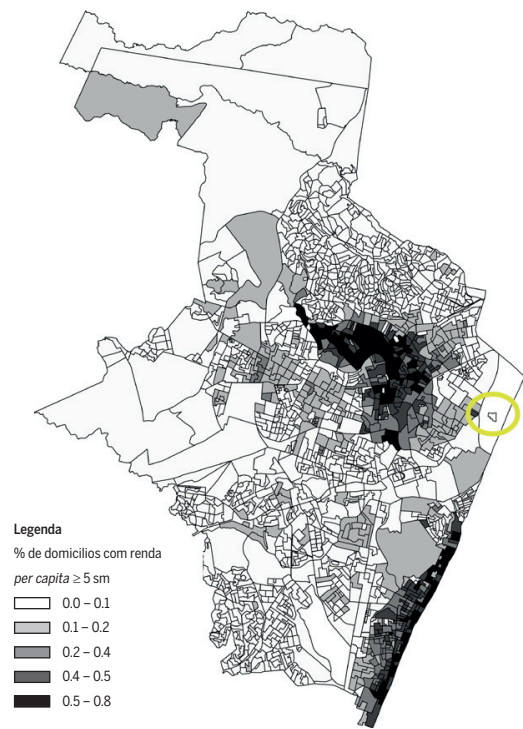

Fonte: Elaborado pelos autores.

Ampliando a análise para além da dimensão renda, observa-se que os serviços de infraestrutura urbana também tendem a ser distribuídos de maneira desigual ao longo do Recife, privilegiando as áreas com maior percentual de ricos em detrimento das demais. Nesse sentido, os mais pobres não apenas sofrem pela privação de renda, mas também pela falta de serviços urbanos adequados, por exemplo, saneamento básico.

Sobre a energia elétrica, embora sua disponibilidade seja universal no Recife, os problemas que envolvem a qualidade, segurança e regularização do seu fornecimento ainda não foram completamente sanados. A adequação do serviço de energia ocorre quando o domicílio recebe energia elétrica de companhia distribuidora e possui medidor de uso exclusivo. $\bigcirc$ painel (b) mostra que as áreas que apresentaram os menores percentuais de domicílios com energia elétrica com medidor exclusivo coincidem com as áreas que abrigam os mais pobres. 
Figura 2 Características censitárias do Recife em 2010

a) Banheiro de uso exclusivo -

Rede geral de esgoto ou pluvial

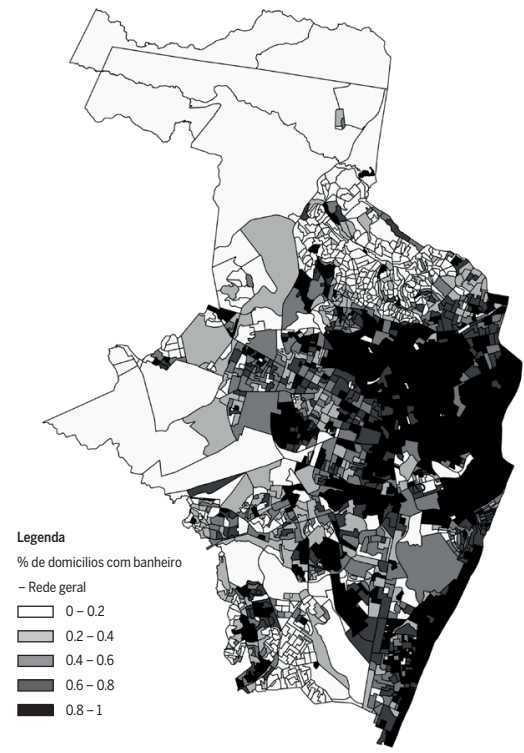

c) Abastecimento de água-rede geral

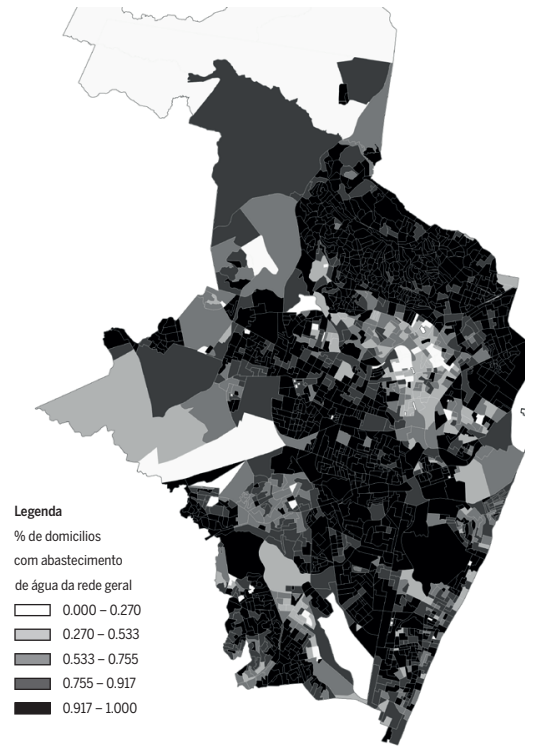

b) Energia elétrica com medidor de uso exclusivo

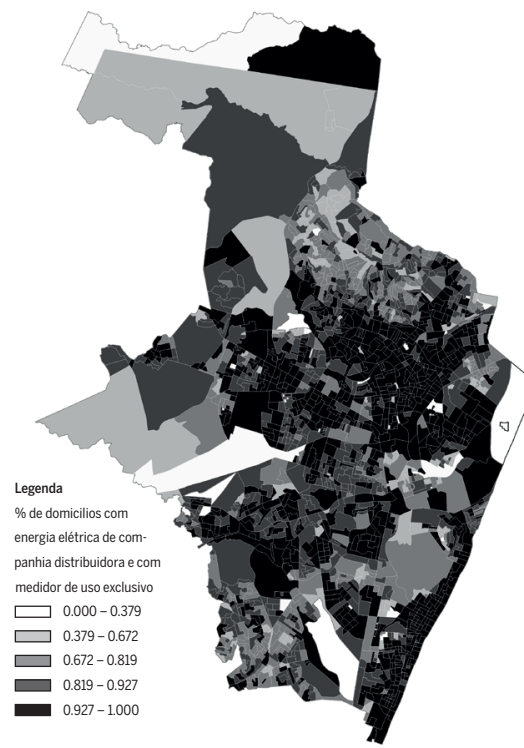

d) Alfabetizados - 7 a 14 anos

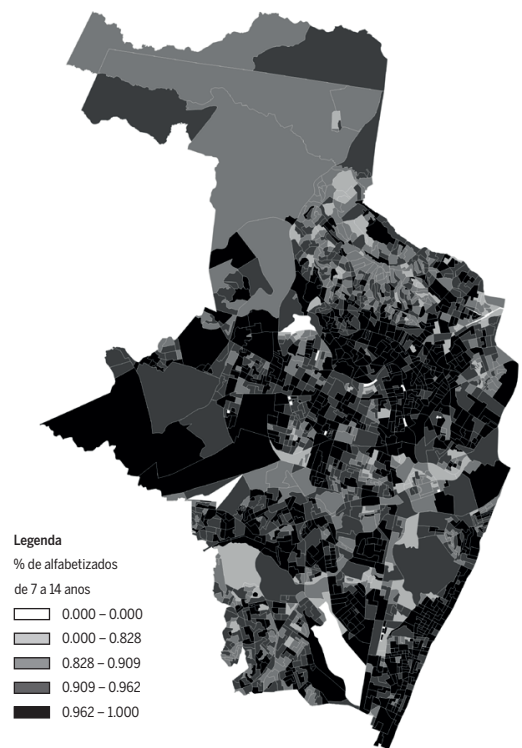


e) Alfabetizados - 25 anos ou mais

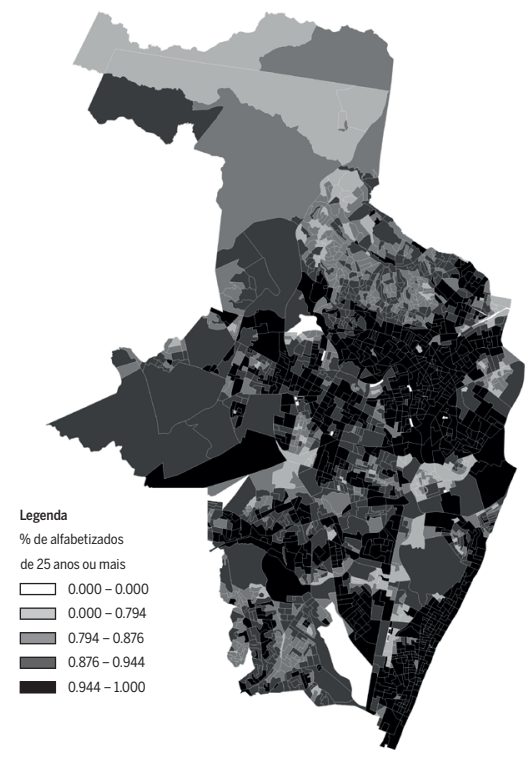

g) Pessoas com idade entre 5 e 14 anos

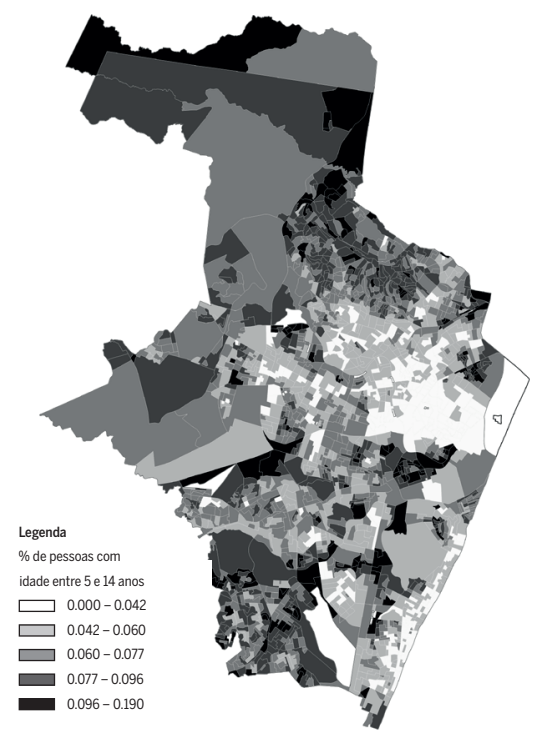

Fonte: Elaborado pelos autores. f) Brancos

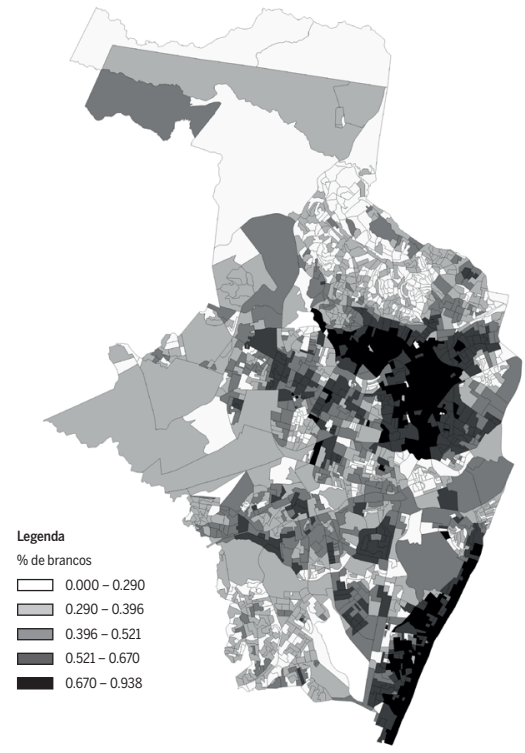


Quanto ao abastecimento de água, painel (c), cabe destacar que apesar de os setores censitários mais pobres apresentarem altos percentuais de domicílios abastecidos por rede geral de distribuição, não se pode garantir que a população residente nessas localidades receba água de forma adequada, já que o racionamento de água é frequente no Recife. Em 2013, ano da realização da pesquisa pela Fundaj, houve racionamento de água em Recife, quando 74 dos 94 bairros da capital foram abastecidos em dias alternados. Como esse evento pode influenciar os resultados dos exercícios econométricos, optou-se por não utilizar a variável água na construção da variável vizinhança.

Adicionalmente, as regiões que reúnem os mais ricos e que possuem as melhores infraestruturas urbanas são também as que abrigam as maiores frações de alfabetizados e de brancos e os menores percentuais de pessoas entre 5 a 14 anos.

\section{Figura 3 Localização dos alunos e das escolas em Recife}

\section{a) Localização dos alunos que moram} em Recife

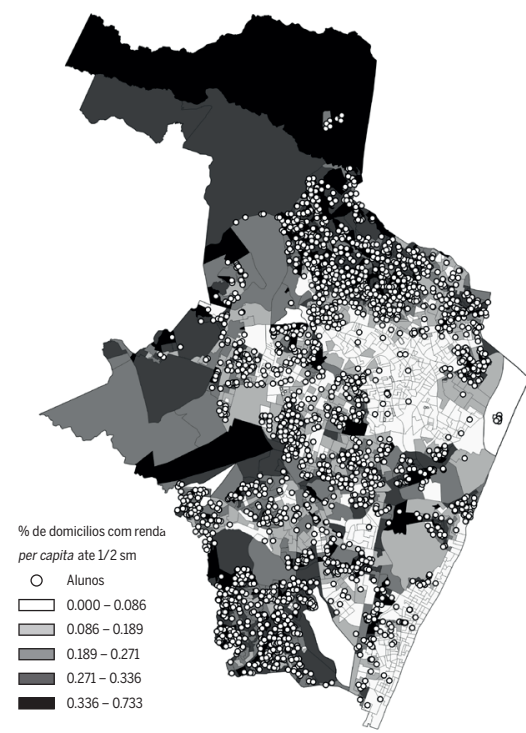

b) Localização das escolas pesquisadas em Recife

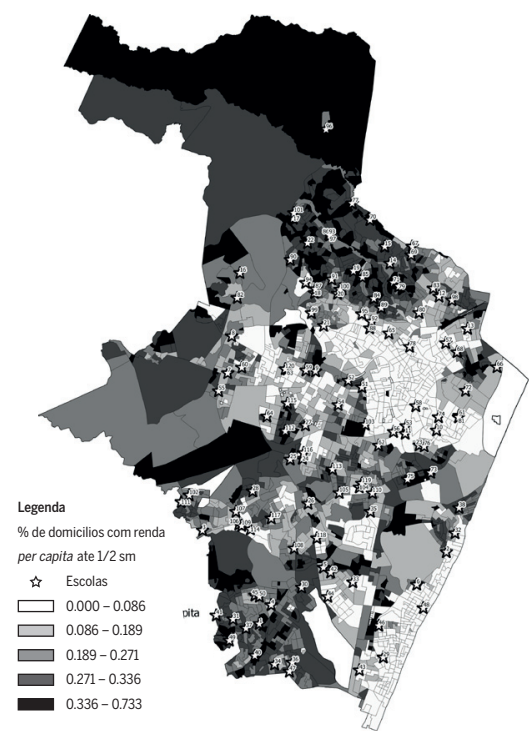

Fonte: Elaborado pelos autores. 
A Figura 3 ilustra a distribuição dos alunos e das escolas em Recife. Nota-se maior concentração de alunos e escolas nas áreas mais carentes. Nessa cidade, as matrículas nas escolas públicas são vinculadas ao local moradia do aluno, o que pode induzir a criança a frequentar uma unidade escolar próxima à sua residência. Ao mesmo tempo que essa política pode favorecer o acesso das crianças a uma unidade escolar, ela também pode potencializar a homogeneidade socioeconômica das escolas localizadas nas áreas mais pobres, onde os estudantes mais pobres não teriam interação com colegas que possuem características socioeconômicas diferentes das suas (Jencks; Mayer, 1990).

\section{Estratégia empírica}

Identificar o verdadeiro impacto da interação social sobre os resultados individuais é um grande desafio empírico devido à existência de endogeneidade decorrente de características não observáveis e do viés de seleção (Manski, 1993; Moffit, 2001; Durlauf, 2004).

Tratando-se especificamente do efeito vizinhança, os indivíduos que vivem na mesma vizinhança tendem a apresentar resultados semelhantes. No entanto, não é claro se isso é devido à semelhança no perfil socioeconômico ou se é porque eles influenciam uns aos outros ou, ainda, porque eles compartilham das mesmas características não observáveis (Goux; Maurin, 2007). Conforme Gibbons et al. (2013), os desempenhos similares obtidos por crianças que vivem em uma determinada vizinhança podem ser decorrência da semelhança em termos de background familiar.

$\mathrm{Na}$ presença de um potencial sorting residencial, a indisponibilidade de dados longitudinais, que possibilitariam o acompanhamento da trajetória do aluno e de seu local de moradia, é um fator bastante limitante, vez que as informações do tipo cross-section demandam a existência de variáveis instrumentais adequadas, quase sempre indisponíveis.

Outro desafio se refere à definição a priori do grupo de vizinhos. Não existe um consenso sobre quem constitui o grupo de referência de cada indivíduo. Goux e Maurin (2007) argumentam que menores vizinhanças, em termos de escala geográfica, parecem ser preferíveis a maiores, partindo do princípio de que os vizinhos distantes têm menor influência do que os mais próximos. Todavia, Lindahl (2010) afirma que, embora as vizinhan- 
ças restritas provavelmente capturem melhor os efeitos das interações sociais, é factível imaginar indivíduos sendo influenciados por seus vizinhos mesmos não tendo contato direto.

No Brasil não existe uma base de dados oficial capaz de solucionar todos esses problemas, contudo a pesquisa realizada pela Fundaj nas escolas públicas do Recife em 2013 reuniu informações que tornam sua utilização particularmente adequada para esta pesquisa, em especial, a localização exata dos alunos e das escolas do Recife, permitindo a construção da variável de vizinhança para cada aluno baseada em pequenas áreas geográficas.

Além disso, o banco de dados também inova ao oferecer grande diversidade de informações individuais, familiares e escolares que tipicamente se correlacionam com a vizinhança e com o resultado escolar.

\subsection{A especificação do modelo empírico}

Este estudo se propõe a estimar os parâmetros do seguinte modelo:

$$
Y_{i n s}=Z_{n} \varphi+X_{i}^{\prime} \gamma+E_{s} \delta+\beta Y_{i n s}^{0}+\varepsilon_{i n s}
$$

em que $Y_{\text {ins }}$ refere-se à nota da prova de matemática no final do ano do estudante $i$ que vive na vizinhança $n$ e frequenta a escola $s ; Z_{n}$ é a variável que reporta a correlação entre as características da vizinhança e a variável dependente; o vetor $X_{i}$ contém características observáveis dos alunos e da sua família; o vetor $E_{s}$ capta as características das escolas; e, por fim, $Y_{\text {ins }}^{0}$ refere-se à nota de matemática no início do ano e capta o background educacional inicial do aluno.

A nota inicial é utilizada para mitigar os problemas ocasionados pelas características não observáveis do aluno que potencialmente influenciam o desempenho escolar. Essa estratégia foi proposta Ding e Lehrer (2007), segundo os quais a nota inicial do aluno seguiria o processo de Markov, de tal forma que os efeitos dos fatores observáveis e não observáveis anteriores a $t-1$ se ajustariam a uma mesma taxa, sendo, posteriormente, empregada por Raposo et al. (2015), quando investigaram o efeito dos pares sobre o desempenho escolar a partir da estrutura da rede de amizades do aluno dentro da sala de aula nas escolas públicas do Recife. 
Diferentemente do desempenho em matemática, Fundaj (2003) disponibiliza as informações sobre as características dos alunos e das escolas em apenas um momento no tempo, o que impossibilita o acompanhamento da trajetória do aluno e de seu local de moradia ao longo do tempo e, consequentemente, o emprego de técnicas econométricas na estrutura de painel.

A variável $Z_{n}$ é um índice representativo de vizinhança obtido a partir do emprego da técnica de componente principal, a exemplo do que foi feito por Bolster et al. (2007) e Solis (2008). Tal variável reúne em uma única medida as informações sobre o acesso a infraestrutura urbana e as características sociodemográficas da vizinhança do aluno $i$.

A elaboração desse índice permite investigar se o desempenho dos alunos da rede pública do Recife está associado à forma como a cidade está territorialmente organizada. Todavia não possibilita a análise dos mecanismos pelos quais o local de moradia exerceria essa influência. Tendo em vista que essa é uma questão importante do ponto de vista de políticas públicas, a análise será ampliada com o intuito de investigar o efeito dos colegas de vizinhança sobre o desempenho escolar. Para tanto, será estimado um modelo linear-in-means, em que o desempenho de um aluno é considerado como função linear das covariadas e da média das características dos pares da vizinhança. Essa estratégia é similar àquela utilizada por Gibbons et al. (2013).

Para viabilizar o emprego da última estratégia econométrica, a variável $Z_{n}$ passa a captar as características médias dos estudantes vizinhos do $i$ -ésimo aluno. Assim, os dados individuais de todos os estudantes do sexto ano que vivem na mesma vizinhança do i-ésimo estudante serão utilizados para a elaboração da variável vizinhança. Serão consideradas apenas as vizinhanças que possuem quatro ou mais estudantes.

$\mathrm{Na}$ ausência de um consenso sobre quais características da vizinhança realmente afetam o desempenho escolar, a construção das variáveis dos pares será baseada no trabalho de Gibbons et al. (2013), que se faz a partir das seguintes variáveis: o percentual de estudantes deficientes como uma proxy para a dificuldade de aprendizagem; o percentual de estudantes beneficiários do Programa Bolsa Família como um indicador de famílias com baixo nível socioeconômico; o percentual de homens, variável amplamente destacada na literatura sobre peer effects; e o percentual de repetentes como um indicador de colegas que têm dificuldade de progredir nos estudos. Como o objetivo é analisar efeitos potenciais de cada uma dessas 
características, em vez do efeito de cada característica condicional a outra, os coeficientes dessas variáveis serão obtidos a partir de uma regressão separada (Gibbons et al., 2013).

Quanto à definição do raio de vizinhança, este estudo iniciará a análise de vizinhança a partir da menor unidade geográfica para a qual dispomos de informações censitárias que é o setor censitário. Na sequência, assim como feito por Bolster (2007) e Gibbons et al. (2013), essa definição de vizinhança será expandida através da construção de mais dois raios: a) os setores censitários (ou alunos vizinhos, quando a análise for para os grupos de pares da vizinhança) que estão em um raio $250 \mathrm{~m}$; b) setores censitários (alunos vizinhos) que estão em um raio de $500 \mathrm{~m}$.

\subsection{Bases de dados e as estatísticas descritivas}

Os dados utilizados neste estudo são derivados da pesquisa realizada pela Fundaj em 2013, quando entrevistou diretores, professores, responsáveis e alunos do sexto ano das escolas públicas de Recife. De maneira complementar, foram utilizados os dados do Instituto Nacional de Estudos e Pesquisas Educacionais (INEP) (2014) e do Censo escolar/INEP (2013) para reunir informações das características das escolas analisadas. Por fim, também serão utilizados os dados do Censo Demográfico (2010) para realizar a análise de componentes principais.

A amostra final de alunos, após retirar os estudantes que tinham missing em pelo menos uma variável de controle e de interesse, é de 2.570 alunos de 117 escolas da rede pública de ensino, distribuídos em 142 turmas diferentes do sexto ano. A variável dependente adotada será a nota da segunda prova de matemática.

primeiro estágio da análise consiste em elaborar o índice de qualidade da vizinhança com base nas informações do Censo Demográfico de 2010, em que serão resumidas numa única medida as informações sobre a proporção de domicílios chefiados por mulheres, com renda domiciliar per capita de até $1 / 2$ salário mínimo, com banheiro de uso exclusivo e esgotamento sanitário via rede geral de esgoto, com energia elétrica e medidor exclusivo, além da parcela de pessoas brancas, do sexo masculino, com idade entre 5 e 14 anos, alfabetizadas com idade entre 7 e 14 anos e alfabetizadas com 25 anos ou mais. 
Tabela 1 Características dos alunos e dos responsáveis

\begin{tabular}{|c|c|c|c|}
\hline Variáveis & Descrição das variáveis & Média & $\begin{array}{l}\text { Desvio } \\
\text { padrão }\end{array}$ \\
\hline Nota 2 & Nota de matemática no final do ano & 38,87 & 15,09 \\
\hline Nota 1 & Nota de matemática no início do ano & 41,96 & 15,91 \\
\hline Idade & Idade (anos) & 11,32 & 0,96 \\
\hline Sexo masculino & Aluno é do sexo masculino=1 & $48,70 \%$ & $49,99 \%$ \\
\hline Cor branca & Aluno se autodeclara branco $=1$ & $19,15 \%$ & $39,36 \%$ \\
\hline Repetente & $\begin{array}{l}\text { Aluno já foi reprovado pelo menos uma } \\
\text { vez=1z }\end{array}$ & $26,44 \%$ & $44,11 \%$ \\
\hline Deficiente & Aluno possui alguma deficiência=1 & $3,44 \%$ & $18,22 \%$ \\
\hline Creche & Aluno frequentou creche $=1$ & $70,26 \%$ & $45,72 \%$ \\
\hline Religiosidade & Aluno sempre frequenta igreja/culto=1 & $37,96 \%$ & $48,54 \%$ \\
\hline Sexo masculino & Responsável é do sexo masculino=1 & $13,11 \%$ & $33,75 \%$ \\
\hline $\begin{array}{l}\text { Idade do } \\
\text { responsável }\end{array}$ & Idade do responsável em anos & 38,49 & 8,42 \\
\hline $\begin{array}{l}\text { Escolaridade } \\
\text { do responsável }\end{array}$ & Anos de estudos do responsável & 8,75 & 3,37 \\
\hline $\begin{array}{l}\text { Estado civil } \\
\text { do responsável }\end{array}$ & $\begin{array}{l}\text { Responsável é casado ou possui união } \\
\text { estável=1 }\end{array}$ & $53,59 \%$ & $49,88 \%$ \\
\hline $\begin{array}{l}\text { Empregado com } \\
\text { carteira assinada }\end{array}$ & $\begin{array}{l}\text { Responsável é empregado com carteira } \\
\text { assinada=1 }\end{array}$ & $18,46 \%$ & $38,80 \%$ \\
\hline $\begin{array}{l}\text { Empregado sem } \\
\text { carteira assinada }\end{array}$ & $\begin{array}{l}\text { Responsável é empregado sem carteira } \\
\text { assinada=1 }\end{array}$ & $7,75 \%$ & $26,75 \%$ \\
\hline Conta própria & Responsável é conta própria=1 & $21,48 \%$ & $41,08 \%$ \\
\hline $\begin{array}{l}\text { Empregado doméstico } \\
\text { com carteira assinada }\end{array}$ & $\begin{array}{l}\text { Responsável é empregado doméstico sem } \\
\text { carteira assinada=1 }\end{array}$ & $0,47 \%$ & $6,81 \%$ \\
\hline $\begin{array}{l}\text { Empregado doméstico } \\
\text { sem carteira assinada }\end{array}$ & $\begin{array}{l}\text { Responsável é empregado doméstico com } \\
\text { carteira assinada=1 }\end{array}$ & $1,05 \%$ & $10,18 \%$ \\
\hline Funcionário público & Responsável é funcionário público=1 & $0,66 \%$ & $8,09 \%$ \\
\hline Empregador & Responsável é empregador=1 & $0,08 \%$ & $2,78 \%$ \\
\hline Bolsa família & Beneficiário do Bolsa Família=1 & $57,77 \%$ & $49,40 \%$ \\
\hline Confere o boletim & $\begin{array}{l}\text { Responsável sempre confere o boletim } \\
\text { escolar=1 }\end{array}$ & $84,48 \%$ & $36,22 \%$ \\
\hline $\begin{array}{l}\text { Participa do } \\
\text { conselho escolar }\end{array}$ & $\begin{array}{l}\text { Responsável participa do conselho } \\
\text { escolar=1 }\end{array}$ & $56,69 \%$ & $49,56 \%$ \\
\hline $\begin{array}{l}\text { Mãe não mora } \\
\text { no domicílio }\end{array}$ & $\begin{array}{l}\text { Mãe não mora, mas o pai mora no } \\
\text { domicílio=1 }\end{array}$ & $4,15 \%$ & $19,95 \%$ \\
\hline
\end{tabular}


Tabela 1 (continuação)

\begin{tabular}{|c|c|c|c|}
\hline Variáveis & Descrição das variáveis & Média & $\begin{array}{l}\text { Desvio } \\
\text { padrão }\end{array}$ \\
\hline $\begin{array}{l}\text { Pai não mora } \\
\text { no domicílio }\end{array}$ & $\begin{array}{l}\text { Pai não mora, mas a mãe mora no } \\
\text { domicílio=1 }\end{array}$ & $43,27 \%$ & $49,55 \%$ \\
\hline $\begin{array}{l}\text { Pai e mãe não moram } \\
\text { no domicílio }\end{array}$ & $\begin{array}{l}\text { Nem o pai nem a mãe moram no } \\
\text { domicílio=1 }\end{array}$ & $8,76 \%$ & $28,28 \%$ \\
\hline $\begin{array}{l}\text { Número } \\
\text { de pessoas }\end{array}$ & $\begin{array}{l}\text { Número de pessoas que moram no } \\
\text { domicílio }\end{array}$ & 4,62 & 1,66 \\
\hline Proximidade & Adotou o critério "proximidade"=1 & $45,17 \%$ & $49,78 \%$ \\
\hline Qualidade & Adotou o critério "qualidade"=1 & $26,95 \%$ & $44,38 \%$ \\
\hline $\begin{array}{l}\text { Facilidade } \\
\text { de matrícula }\end{array}$ & $\begin{array}{l}\text { Adotou o critério "facilidade de } \\
\text { matrícula"=1 }\end{array}$ & $12,49 \%$ & $33,06 \%$ \\
\hline Condição financeira & Adotou o critério "condição financeira"=1 & $6,13 \%$ & $23,99 \%$ \\
\hline $\begin{array}{l}\text { Outro filho/amigo } \\
\text { estuda na escola }\end{array}$ & Adotou o critério "outro filho/amigo"=1 & $5,97 \%$ & $23,70 \%$ \\
\hline $\begin{array}{l}\text { Facilidade } \\
\text { de locomoção }\end{array}$ & $\begin{array}{l}\text { Adotou o critério "facilidade de } \\
\text { locomoção"=1 }\end{array}$ & $0,35 \%$ & $5,90 \%$ \\
\hline $\begin{array}{l}\text { Outros motivos da } \\
\text { escolha da escola }\end{array}$ & Adotou o critério "outros motivos"=1 & $2,95 \%$ & $16,91 \%$ \\
\hline $\begin{array}{l}\text { Distância percorrida } \\
\text { pelo aluno }\end{array}$ & $\begin{array}{l}\text { Distância entre a residência do aluno e a } \\
\text { escola }\end{array}$ & 0,85 & 0,93 \\
\hline $\begin{array}{l}\text { Se o aluno vai andando } \\
\text { para a escola }\end{array}$ & Aluno vai andando para a escola $=1$ & $79,07 \%$ & $40,69 \%$ \\
\hline Nasceu no bairro & Adotou o critério "nasceu no bairro"=1 & $28,81 \%$ & $45,30 \%$ \\
\hline $\begin{array}{l}\text { Adquiriu casa/ } \\
\text { apartamento }\end{array}$ & $\begin{array}{l}\text { Adotou o critério "adquiriu casa/ } \\
\text { apartamento"=1 }\end{array}$ & $28,77 \%$ & $45,28 \%$ \\
\hline Perto de familiares & Adotou o critério "perto de familiares"=1 & $20,05 \%$ & $40,04 \%$ \\
\hline Condição financeira & Adotou o critério "condição financeira"=1 & $11,90 \%$ & $32,39 \%$ \\
\hline Perto do trabalho & Adotou o critério "perto do trabalho"=1 & $2,99 \%$ & $17,02 \%$ \\
\hline Perto da escola & Adotou o critério "perto da escola"=1 & $1,67 \%$ & $12,81 \%$ \\
\hline $\begin{array}{l}\text { Outros motivos da escolha } \\
\text { do local de moradia }\end{array}$ & Adotou o critério "outros motivos"=1 & $4,54 \%$ & $20,81 \%$ \\
\hline
\end{tabular}

Fonte: Elaborado pelos autores. 
Tabela 2 Características das escolas

\begin{tabular}{|c|c|c|c|}
\hline Variáveis & Descrição das variáveis & Média & $\begin{array}{l}\text { Desvio } \\
\text { padrão }\end{array}$ \\
\hline Escola Estadual & $\begin{array}{l}\text { Escola pertence à rede estadual de } \\
\text { ensino }=1\end{array}$ & $76,07 \%$ & $42,85 \%$ \\
\hline Ciclo & Escola adota o regime de ciclo $=1$ & $35,04 \%$ & $47,92 \%$ \\
\hline Biblioteca & $\begin{array}{l}\text { Escola possui biblioteca em quantidade } \\
\text { suficiente e condição adequada=1 }\end{array}$ & $67,52 \%$ & $47,03 \%$ \\
\hline Quadra de esporte & $\begin{array}{l}\text { Escola possui quadra de esporte em } \\
\text { quantidade suficiente e condição } \\
\text { adequada=1 }\end{array}$ & $24,79 \%$ & $43,36 \%$ \\
\hline Laboratório & $\begin{array}{l}\text { Escola possui laboratório em quantidade } \\
\text { suficiente e condição adequada=1 }\end{array}$ & $40,17 \%$ & $49,24 \%$ \\
\hline $\begin{array}{l}\text { Acesso de internet } \\
\text { aos alunos }\end{array}$ & $\begin{array}{l}\text { Acesso à internet para o uso dos alunos } \\
\text { em quantidade suficiente e condição } \\
\text { adequada }=1\end{array}$ & $29,91 \%$ & $45,99 \%$ \\
\hline $\begin{array}{l}\text { Acesso de internet } \\
\text { aos professores }\end{array}$ & $\begin{array}{l}\text { Acesso à internet para o uso dos } \\
\text { professores em quantidade suficiente e } \\
\text { condição adequada=1 }\end{array}$ & $39,32 \%$ & $49,06 \%$ \\
\hline Alunos por computador & Alunos por computador & 75,33 & 84,3 \\
\hline $\begin{array}{l}\text { Nível socioeconômico } \\
\text { (INSE)* }\end{array}$ & Valor do INSE & 3,8 & 0,48 \\
\hline $\begin{array}{l}\text { Carência de pessoal } \\
\text { de apoio pedagógico }\end{array}$ & $\begin{array}{l}\text { Carência de pessoal de apoio pedagógico } \\
\text { (coordenador, supervisor e orientador } \\
\text { educacional)=1 }\end{array}$ & $45,30 \%$ & $49,99 \%$ \\
\hline $\begin{array}{l}\text { Complexidade } \\
\text { da gestão escolar** }\end{array}$ & Indicador de complexidade escolar & 4,85 & 0,96 \\
\hline $\begin{array}{l}\text { Indicador de esforço } \\
\text { do docente } \\
\text { (proporção) }\end{array}$ & Professores de elevado esforço & $9,77 \%$ & $8,21 \%$ \\
\hline \multicolumn{4}{|l|}{$\begin{array}{l}\text { Indicador de adequação } \\
\text { do docente } \\
\text { (proporção) }\end{array}$} \\
\hline Grupo 1 & Docentes que pertencem ao grupo 1 & $61,83 \%$ & $11,69 \%$ \\
\hline Grupo 2 & Docentes que pertencem ao grupo 2 & $1,91 \%$ & $3,74 \%$ \\
\hline Grupo 3 & Docentes que pertencem ao grupo 3 & $31,77 \%$ & $10,08 \%$ \\
\hline Grupo 4 & Docentes que pertencem ao grupo 4 & $3,45 \%$ & $5,30 \%$ \\
\hline Grupo5 & Docentes que pertencem ao grupo 5 & $1,27 \%$ & $2,90 \%$ \\
\hline
\end{tabular}


Tabela 2 (continuação)

\begin{tabular}{llr|r}
\hline Variáveis & Descrição das variáveis & Média & $\begin{array}{r}\text { Desvio } \\
\text { padrão }\end{array}$ \\
\hline Tamanho da turma & Alunos por turma & 36,18 & 7,5 \\
\hline Turno manhã & Aulas matutinas=1 & $76,08 \%$ & $42,67 \%$ \\
\hline $\begin{array}{l}\text { Professor da turma } \\
\text { possui licenciatura em } \\
\text { matemática }\end{array}$ & $\begin{array}{l}\text { Professor possui licenciatura em } \\
\text { matemática=1 }\end{array}$ & $32,39 \%$ & $46,96 \%$ \\
\hline $\begin{array}{l}\text { Professor da turma } \\
\text { é concursado }\end{array}$ & Professor é concursado=1 & $39,44 \%$ & $49,04 \%$ \\
\hline $\begin{array}{l}\text { Inexistência de professor } \\
\text { de matemática }\end{array}$ & Não havia professor de matemática=1 & $0,85 \%$ & $9,25 \%$ \\
\hline $\begin{array}{l}\text { Paralisação das atividades } \\
\text { escolares durante o ano } \\
\text { de 2013 }\end{array}$ & $\begin{array}{l}\text { Houve paralisação das atividades } \\
\text { escolares no decorrer do ano de 2013=1 }\end{array}$ & $43,66 \%$ & $49,77 \%$ \\
\hline $\begin{array}{l}\text { Escolas que o professor } \\
\text { de matemática trabalha }\end{array}$ & $\begin{array}{l}\text { Número de escolas que o professor de } \\
\text { matemática trabalha }\end{array}$ & 1,65 & 0,61 \\
\hline
\end{tabular}

Fonte: Elaborado pelos autores.

Notas: * O nível socioeconômico dos alunos foi construído a partir das respostas dos estudantes aos questionários contextuais das duas avaliações do Sistema de Avaliação da Educação Básica (Saeb) e do Exame Nacional do Ensino Médio (Enem). As questões utilizadas dizem respeito à renda familiar, à posse de bens e contratação de serviços de empregados domésticos pela família dos estudantes e ao nivel de escolaridade de seus pais ou responsáveis (INEP, 2015).

** O indicador de complexidade de gestão das escolas resume, em uma única medida, as informações de porte, turnos de funcionamento, nível de complexidade das etapas e quantidade de etapas ofertadas (INEP, 2014c).

*** O indicador do esforço docente resume, em uma única medida, os aspectos do trabalho do professor que contribuem para a sobrecarga no exercício da profissão. É mensurado a partir do percentual de docentes cujo esforço para o exercício da profissão é considerado elevado. Os docentes com esforço elevado nos anos finais possuem, de forma geral, as seguintes características: atendem mais de 400 alunos, atuam em turmas que funcionam nos três turnos, em duas ou mais etapas e em duas ou mais escolas (INEP, 2014b).

**** O indicador de adequação da formação do docente busca classificar os docentes segundo a adequação de sua formação inicial na disciplina e a etapa de atuação na educação básica (INEP, 2014a). 
Para controlar os efeitos das características individuais serão utilizadas as informações sobre o sexo, cor, idade, religiosidade, se frequentou a pré-escola e indicadores deficiência e de repetência dos estudantes. Além disso, será utilizada a nota da primeira prova para captar as características não observáveis dos alunos que não variam no tempo (Ding; Lehrer, 2007).

As variáveis utilizadas para captar as influências do ambiente familiar são idade, estado civil, escolaridade e ocupação dos responsáveis pelos alunos, dummies que identificam se os pais moram no domicílio, dummy que identifica se família é beneficiária do Programa Bolsa Família e o número de pessoas residentes no domicílio. Além disso, foram incluídas dummies se o responsável confere o boletim, se participa de conselho escolar, quais os critérios adotados para a escolha da escola e o meio de transporte utilizado pelo aluno para chegar até a escola. Por fim, os critérios de escotha do local de moradia também foram utilizados para atenuar os possíveis vieses de variáveis omitidas não observáveis que são correlacionadas com o local de moradia.

A Tabela 1 revela que os estudantes têm, em média, 11 anos de idade, $48,70 \%$ deles são do sexo masculino, $19,15 \%$ são brancos, $3,44 \%$ possuem alguma deficiência física e $37,96 \%$ sempre frequentam igreja/culto. Aproximadamente 1/4 dos alunos já repetiu de série pelo menos uma vez. Apenas $44 \%$ dos alunos moram com a mãe e o pai no mesmo domić́lio.

Quanto ao perfil dos responsáveis, a maioria é mulher com idade média de 39 anos e que estudaram em torno de nove anos. Aproximadamente metade dos responsáveis trabalha, sendo que $21,48 \%$ deles ocupam a posição de conta própria. É significativa a fração de alunos beneficiários do Programa Bolsa Família - quase $60 \%$.

A proximidade é o principal critério de escolha da escola, sendo citado por $45,17 \%$ dos responsáveis pesquisados. Sobre a escolha do bairro, nascer no bairro $(28,81 \%)$, adquirir um imóvel $(28,77 \%)$ e perto da família $(20,05 \%)$ são os principais motivos adotados pelos responsáveis entrevistados para decidir o local de moradia.

Em relação às escolas, foi identificada a rede de ensino; se possui biblioteca, quadra de esportes, laboratório, internet para o professor e para o aluno em quantidades suficientes e condições adequadas.

Para captar a complexidade de gestão escolar, foi adotado o indicador calculado pelo INEP (2014c) que resume as informações de porte, turnos de funcionamento, nível de complexidade das etapas e quantidade de eta- 
pas ofertadas. O INEP (2014c) definiu seis níveis de complexidade, em que os níveis mais elevados indicam maior complexidade. Nenhuma escola recifense analisada possui nível de complexidade 1.

$O$ indicador do esforço docente mensura os aspectos do trabalho do professor que contribuem para a sobrecarga no exercício da profissão. O INEP (2014b) calculou esse índice com base no percentual de docentes que atendem mais de 400 alunos, atuam em turmas que funcionam nos três turnos, em duas ou mais etapas e em duas ou mais escolas.

Ademais, foi utilizado o indicador de adequação da formação do docente para captar a adequação da formação inicial docente à disciplina e a etapa de atuação na educação básica. O INEP (2014a) definiu cinco grupos, quais sejam: Grupo 1 - Docentes com formação superior de licenciatura na mesma disciplina que lecionam, ou bacharelado na mesma disciplina com curso de complementação pedagógica concluído; Grupo 2 - Docentes com formação superior de bacharelado na disciplina correspondente, mas sem licenciatura ou complementação pedagógica; Grupo 3 - Docentes com licenciatura em área diferente daquela que leciona, ou com bacharelado nas disciplinas da base curricular comum e complementação pedagógica concluída em área diferente daquela que leciona; Grupo 4 - Docentes com outra formação superior não considerada nas categorias anteriores; Grupo 5 - Docentes que não possuem curso superior completo.

Em relação às características da turma, foram inseridas na análise informações sobre a quantidade de alunos por turma, turno em que as aulas ocorrem, se o professor é licenciado em matemática, se o professor é concursado, quantidades de escolas que o professor de matemática leciona, existência de professor na disciplina e ocorrência de interrupção das atividades escolares durante o ano de 2013.

A pesquisa realizada pela Fundaj revelou que $66,67 \%, 25 \%$ e $40 \%$ das unidades escolares possuem biblioteca, quadras de esporte e laboratório em número e condições adequadas, respectivamente. Observa-se também o elevado número médio de aluno por computador, em torno de 75 , conforme a Tabela 2.

As informações do INEP (2014a) mostram que mais de 90\% dos professores possuem licenciatura ou bacharelado com curso de complementação pedagógica, porém 1/3 deles ministram disciplinas diferentes da sua área de formação. Além disso, 1 em cada 10 professores das escolas pesquisadas é considerado como "alto esforço", isto é, atende mais de 400 alunos e 
atua em turmas que funcionam nos três turnos, em duas ou mais etapas e em duas ou mais escolas.

As estatísticas das turmas indicam que a maioria dos alunos estuda no turno da manhã em salas de aula com 36 estudantes, em média. Menos da metade dos professores que lecionam a disciplina de matemática possuem licenciatura em matemática e são concursados. $\bigcirc$ problema da falta de professor da disciplina de matemática atingiu aproximadamente 0,85\% das turmas em 2013.

Por fim, como são frequentes os casos em que os estudantes e/ou os pares da vizinhança estudam em escolas situadas fora do raio de vizinhança estipulado neste estudo, pode-se argumentar que o desempenho acadêmico individual possa sofrer influências de outras vizinhanças (em média, cada turma reúne alunos de 15 setores censitários distintos). Para tentar atenuar esse efeito, duas variáveis de distância são utilizadas como controle. A primeira variável mensura a distância da residência do estudante até a escola, pois os alunos que estudam em escolas muito distantes, além de serem potencialmente influenciados por outras vizinhanças, eles também podem ser diferenciados (maior preocupação da família com o estudo, por exemplo). Já a segunda variável leva em consideração a distância média da residência do estudante até a escola dos seus pares, pois é factível imaginar que os pares que estudam em escolas muito distantes podem trazer influências de outras vizinhanças.

\section{Resultados}

Nesta seção serão apresentados os resultados das estimações dos modelos de regressão linear para as duas variáveis de vizinhança propostas na metodologia. Na seção 4.1 será investigada uma possível associação do desempenho escolar com as características censitárias da vizinhança, ao passo que na seção 4.2 será analisada uma potencial relação entre o aprendizado em matemática e os pares da vizinhança.

\subsection{Análise do componente principal}

A técnica de componentes principais foi utilizada para a construção de um 
índice representativo das características da vizinhança que abrangesse os aspectos da infraestrutura urbana, da dinâmica demográfica e das características socioeconômicas.

A Tabela 3 reporta as características das vizinhanças considerando as escalas geográficas: setor censitário, raios de 250 e 500 metros. A primeira coluna da tabela aponta que os estudantes da rede pública de ensino moram em setores que possuem 46,85\%, 40,41\%, 82,26\% dos domicílios com renda per capita de até $1 / 2$ salário mínimo, banheiro via rede geral de esgoto e energia elétrica com medidor exclusivo, respectivamente. Ademais, 91,45\% das pessoas com idade entre 7 e 14 anos residentes nesses setores são alfabetizadas, percentual maior do que aquele observado para pessoas alfabetizadas com 25 anos ou mais. Apenas $1 / 3$ da população é considerada branca.

Tabela 3 Características das vizinhanças (\% de domicílios/pessoas)

\begin{tabular}{lrr|r|r|r|r}
\hline & Setor censitário & \multicolumn{2}{r}{ Raio 250m } & \multicolumn{2}{r}{ Raio 500m } \\
\cline { 2 - 7 } & Média & d.p. & Média & d.p & Média & d.p \\
\hline Renda per capita até 1/2 salário mínimo & $46,85 \%$ & $16,66 \%$ & $44,03 \%$ & $12,95 \%$ & $42,59 \%$ & $11,78 \%$ \\
\hline Banheiro via Rede geral & $40,41 \%$ & $34,72 \%$ & $42,31 \%$ & $26,57 \%$ & $43,29 \%$ & $24,40 \%$ \\
\hline Energia elétrica com medidor de uso exclusivo & $82,26 \%$ & $14,18 \%$ & $83,60 \%$ & $8,18 \%$ & $84,20 \%$ & $6,77 \%$ \\
\hline Mulher responsável & $47,66 \%$ & $9,92 \%$ & $47,59 \%$ & $4,81 \%$ & $47,46 \%$ & $3,71 \%$ \\
\hline Homens & $46,80 \%$ & $1,87 \%$ & $46,64 \%$ & $1,18 \%$ & $46,57 \%$ & $1,04 \%$ \\
\hline Alfabetizadas - 7 a 14 anos & $91,45 \%$ & $5,64 \%$ & $91,43 \%$ & $3,37 \%$ & $91,62 \%$ & $2,69 \%$ \\
\hline Alfabetizadas - 25 anos ou mais & $87,95 \%$ & $6,42 \%$ & $88,91 \%$ & $4,25 \%$ & $89,47 \%$ & $3,56 \%$ \\
\hline Idade entre 5 a 14 anos & $16,48 \%$ & $3,30 \%$ & $16,11 \%$ & $2,39 \%$ & $15,87 \%$ & $2,10 \%$ \\
\hline Brancas & $33,80 \%$ & $9,91 \%$ & $35,05 \%$ & $8,12 \%$ & $35,86 \%$ & $7,62 \%$ \\
\hline
\end{tabular}

Fonte: Elaborado pelos autores.

Quanto maior for o raio de vizinhança dos alunos, maior a probabilidade de definir como vizinhos os setores que são espacialmente desconectados. Dessa forma, a segregação residencial pode ser artificialmente reduzida, pois raios maiores permitem maior interação espacial entre grupos distintos (Oliveira; Silveira Neto, 2016). A partir da Tabela 3 percebe-se que, à medida que o raio de vizinhança aumenta, cresce também a participação daqueles atributos que são típicos das áreas ricas (domicílios com banheiro via rede geral de esgoto, energia elétrica com medidor, pessoas alfabetizadas) e diminui a porcentagem de atributos que são típicos das 
áreas pobres (\% de domicílios com renda per capita até 1/2 salário mínimo, pessoas com idade entre 5 e 14 anos). Ademais, o desvio padrão de todas as variáveis analisadas diminui quando o raio de vizinhança aumenta. As diferenças entre as médias das características entre escalas de vizinhanças consideradas são estatisticamente significantes considerando o nível de $5 \%$ de confiança, com exceção da variável proporção de mulheres responsáveis pelo domicilio ${ }^{4}$.

As próximas duas tabelas reportam os resultados da análise de componentes principais para as três escalas de vizinhança explicadas na metodologia. O primeiro componente explica entre 49,8\% e 67,06\% da variância total dos dados (Tabela 4). O autovetor a ele associado, Tabela 5, atribui pesos positivos às variáveis proporção de banheiros, alfabetizados e brancos e valores negativos às variáveis proporção de domicílios com renda per capita até $1 / 2$ salário mínimo, mulher responsável e pessoas entre $5 \mathrm{e}$ 14 anos. Sendo assim, o primeiro componente principal é essencialmente uma medida de vizinhança privilegiada. Então, espera-se que esse componente tenha relação positiva com o desempenho escolar.

Tabela 4 Componentes principais - autovalores e porcentagem da variância explicada

\begin{tabular}{l|rr|r|r|r|r}
\hline \multirow{2}{*}{$\begin{array}{l}\text { Compo- } \\
\text { nente }\end{array}$} & \multicolumn{2}{|c|}{ Setor censitário } & & Raio 250m & \multicolumn{2}{|c}{ Raio 500m } \\
\cline { 2 - 7 } & Autovalor & $\begin{array}{r}\text { \% da } \\
\text { variância } \\
\text { total }\end{array}$ & Autovalor & $\begin{array}{r}\text { \% da } \\
\text { variância } \\
\text { total }\end{array}$ & Autovalor & $\begin{array}{r}\text { \% da } \\
\text { variância } \\
\text { total }\end{array}$ \\
\hline $\mathbf{1}$ & 4,479 & $49,77 \%$ & 5,633 & $62,59 \%$ & 6,036 & $67,06 \%$ \\
\hline $\mathbf{2}$ & 1,296 & $14,40 \%$ & 1,421 & $15,79 \%$ & 1,436 & $15,96 \%$ \\
\hline $\mathbf{3}$ & 0,780 & $8,67 \%$ & 0,634 & $7,04 \%$ & 0,536 & $5,96 \%$ \\
\hline $\mathbf{5}$ & 0,692 & $7,69 \%$ & 0,430 & $4,77 \%$ & 0,335 & $3,73 \%$ \\
\hline $\mathbf{6}$ & 0,549 & $6,10 \%$ & 0,295 & $3,28 \%$ & 0,219 & $2,44 \%$ \\
\hline $\mathbf{7}$ & 0,467 & $5,19 \%$ & 0,221 & $2,46 \%$ & 0,153 & $1,70 \%$ \\
\hline $\mathbf{8}$ & 0,310 & $3,44 \%$ & 0,162 & $1,80 \%$ & 0,144 & $1,60 \%$ \\
\hline $\mathbf{9}$ & 0,247 & $2,75 \%$ & 0,135 & $1,50 \%$ & 0,097 & $1,08 \%$ \\
\hline
\end{tabular}

Fonte: Elaborado pelos autores.

4 Foram realizados testes para diferenças de características entre as diferentes escalas de vizinhanças empregadas. Em apenas um único caso (variável associada à proporção de mulheres chefes de domicílio) não se rejeita a hipótese de igualdade das características entres as escalas de vizinhanças. 
Tabela 5 Autovetores associados ao componente principal 1 ( $\%$ de domicílios/pessoas)

\begin{tabular}{lrrr}
\hline & Setor censitário & Raio 250m & Raio 500m \\
\hline Renda per capita até 1/2 salário mínimo & $-0,4213$ & $-0,4009$ & $-0,393$ \\
\hline Idade entre 5 e 14 anos & $-0,4099$ & $-0,3901$ & $-0,3819$ \\
\hline Alfabetizadas - 25 anos ou mais & 0,4011 & 0,387 & 0,378 \\
\hline Brancos & 0,3586 & 0,3629 & 0,362 \\
\hline Alfabetizadas - 7 e 14 anos & 0,3448 & 0,337 & 0,3218 \\
\hline Energia elétrica e medidor de uso exclusivo & 0,3371 & 0,3529 & 0,3573 \\
\hline Homens & $-0,3109$ & $-0,3457$ & $-0,3556$ \\
\hline Banheiro e esgotamento sanitário via rede geral & 0,1876 & 0,2183 & 0,261 \\
\hline Mulher responsável & $-0,0259$ & $-0,0201$ & 0,0058 \\
\hline
\end{tabular}

Fonte: Elaborado pelos autores.

O maior peso, em módulo, é atribuído à variável proporção de domicílios com renda per capita até $1 / 2$ salário mínimo, seguido pelo percentual de pessoas com idade entre 5 e 14 anos e pela proporção de pessoas alfabetizadas com 25 anos ou mais. Na sequência, encontram-se o percentual de brancos, a proporção de pessoas alfabetizadas entre 7 e 14 anos, o percentual de domicílios com energia elétrica e medidor exclusivo, fração de homens, percentual de domicílios com banheiro de uso exclusivo via rede geral. Por fim, o menor peso é atribuído à variável percentual de mulheres responsáveis. Esses pesos são tão maiores quanto maior for a dispersão dos valores entre as observações.

A Tabela 6 apresenta o resultado da regressão linear para o caso em que a variável de vizinhança é um índice representativo das caracteristicas censitárias do local de moradia do estudante. Como esperado, os coeficientes estimados reportam a correlação positiva e significativa entre o índice de vizinhança e o desempenho de matemática, sugerindo que os alunos localizados em uma vizinhança mais privilegiada tendem a ter melhor desempenho escolar. Destaca-se a semelhança dos coeficientes estimados para os setores censitários, raio $250 \mathrm{~m}$, raio $500 \mathrm{~m}$.

É importante ressaltar que os coeficientes estimados via regressão linear múltipla não podem ser interpretados como uma relação causal, devido à possibilidade de existência de variáveis omitidas que podem ser correlacionadas com a variável dependente e com as covariadas. Todavia, o presente exercício econométrico avança com a discussão nacional ao mostrar, pela primeira vez, a associação positiva entre o local de moradia e o desempenho escolar em pequenos recortes geográficos. 
Tabela 6 Resultados - Análise componente principal

\begin{tabular}{|c|c|c|c|c|c|c|}
\hline & Modelo 1 & Modelo 2 & Modelo 3 & Modelo 4 & Modelo 5 & Modelo 6 \\
\hline \multicolumn{7}{|l|}{ Setor Censitário } \\
\hline \multirow[t]{2}{*}{ PCA } & $0,749 * * *$ & $0,437^{* * * *}$ & $0,350^{* * *}$ & $0,286^{* *}$ & $0,295^{* *}$ & $0,297^{* *}$ \\
\hline & $(0,161)$ & $(0,12)$ & $(0,12)$ & $(0,124)$ & $(0,123)$ & $(0,123)$ \\
\hline $\mathrm{R}^{2}$ & 0,011 & 0,225 & 0,236 & 0,246 & 0,247 & 0,247 \\
\hline \multicolumn{7}{|l|}{ Raio 250m } \\
\hline \multirow[t]{2}{*}{ PCA } & $0,664^{* * *}$ & $0,444^{* * *}$ & $0,370^{* * *}$ & $0,307^{* *}$ & $0,312^{* *}$ & $0,310^{* *}$ \\
\hline & $(0,151)$ & $(0,114)$ & $(0,112)$ & $(0,115)$ & $(0,115)$ & $(0,115)$ \\
\hline $\mathrm{R}^{2}$ & 0,011 & 0,226 & 0,237 & 0,247 & 0,247 & 0,248 \\
\hline \multicolumn{7}{|l|}{ Raio $500 \mathrm{~m}$} \\
\hline \multirow[t]{2}{*}{ PCA } & $0,640^{* * *}$ & $0,454^{* * *}$ & $0,388^{* * *}$ & $0,342^{* * *}$ & $0,347^{* * *}$ & $0,343^{* * *}$ \\
\hline & $(0,161)$ & $(0,121)$ & $(0,118)$ & $(0,127)$ & $(0,128)$ & $(0,128)$ \\
\hline $\mathrm{R}^{2}$ & 0,011 & 0,226 & 0,237 & 0,247 & 0,248 & 0,248 \\
\hline \multicolumn{7}{|l|}{ Controles } \\
\hline Aluno & Não & Sim & Sim & Sim & Sim & Sim \\
\hline Responsáveis/ domicílio & Não & Não & Sim & Sim & Sim & Sim \\
\hline Escola /turma & Não & Não & Não & Sim & Sim & Sim \\
\hline Escolha do bairro & Não & Não & Não & Não & Sim & Sim \\
\hline Distância da residência a escola & Não & Não & Não & Não & Não & Sim \\
\hline
\end{tabular}

Fonte: Elaborado pelos autores.

Notas: (1) Desvios padrão (corrigidos por cluster de escolas) entre parêntesis; (2) *** $p<0,01$, ${ }^{* *} p<0,05,{ }^{*} p<0,1$.

No modelo 1, sem nenhum controle, a moradia em uma vizinhança mais privilegiada está associada a uma melhora em torno de 0,749 ponto na nota final, em média, quando analisa-se o raio de vizinhança setor censitário. Considerando-se que a nota de matemática varia em um intervalo de 0 a 100 pontos, tal valor do coeficiente estimado indica que uma melhoria da qualidade da vizinhança corresponde a um desvio padrão da medida do componente principal (variação igual a 2,1164) está associada a um incremento da nota de 1,6 ponto da nota ou a cerca de 4,1\% de aumento em relação à nota média dos alunos.

A importância da variável vizinhança é reduzida ao inserir os controles individuais dos alunos na análise, modelo 2. Quando as variáveis do background familiar e da escola como controle são introduzidas na análise, modelos 3 e 4, o coeficiente sofre outra redução, mas permanece significanti- 
vo. Por fim, nos modelos 5 e 6, quando são controlados pelos critérios de escolha do bairro e a distância percorrida pelo aluno para chegar até a escola, o coeficiente estimado pouco altera (quando comparado ao modelo 4). Assim, condicional às caracteristicas individuais, familiares e escolares (modelo 6) e condiderando-se, por exemplo, a vizinhança definida pelo raio de 250 metros, observa-se que uma melhoria da qualidade da vizinhança corresponde a um desvio padrão da medida do componente principal está associada a um incremento da nota de 0,734 ponto da nota ou a cerca de $2 \%$ de aumento em relação à nota média dos alunos.

Com esse exercício econométrico foi possível mostrar que as características da vizinhança parecem exercer influência nos resultados escolares, sugerindo que as melhores perfomances escolares estão associadas às melhores vizinhanças. Essa associação positiva entre a qualidade da vizinhança e a nota do aluno é obtida mesmo depois de considerar as características observáveis e não observáveis (através da nota inicial) que podem afetar o desempenho.

Contudo, uma desvantagem dessa perspectiva, além dos problemas de identificação causal e precisa do efeito, é que não estamos aptos para dizer por quais mecanismos esse efeito opera. Assim, na seção seguinte será investigado se a influência dos pares dos alunos habitantes da mesma vizinhança poderia atuar como um possível mecanismo.

\subsection{0 efeito dos pares de vizinhança}

Nesta seção são exploradas empiricamente, via regressão linear-in-means, as possibilidades de o efeito vizinhança atuar por meio dos pares dos alunos que moram em sua vizinhança, isto é, através de estudantes que residem numa mesma vizinhança (peer effect). As variáveis dos pares de vizinhança foram obtidas a partir do cálculo da proporção de alunos deficientes, homens, beneficiários do Bolsa Família e de repetentes que moram na vizinhança do i-ésimo estudante. Essas proporções estão relacionadas na Tabela 7.

Quanto maior o raio de vizinhança, maior a quantidade média de alunos por vizinhança e o número de escolas frequentadas. Com relação às informações de proporção de deficientes, beneficiários do Bolsa Família, de homens e deficientes, embora não se perceba uma alteração significativa na média entre os raios de vizinhança, há uma redução no desvio padrão, revelando a diminuição da variabilidade das informações. 
Tabela 7 Características dos pares de vizinhança

\begin{tabular}{l|r|r|r|r|r|r}
\hline \multirow{2}{*}{ Variáveis } & \multicolumn{2}{|r|}{ Setor censitário } & & Raio 250m & \multicolumn{2}{r}{ Raio 500m } \\
\cline { 2 - 8 } & Média & $\begin{array}{r}\text { Desvio } \\
\text { padrão }\end{array}$ & Média & $\begin{array}{r}\text { Desvio } \\
\text { padrão }\end{array}$ & Média & $\begin{array}{r}\text { Desvio } \\
\text { padrão }\end{array}$ \\
\hline \# alunos & 6,43 & 3,46 & 9,81 & 5,04 & 25,53 & 12,4 \\
\hline \# de escolas frequentadas & 2,55 & 1,11 & 3,54 & 1,61 & 6,07 & 2,88 \\
\hline \% de Deficientes & $3,73 \%$ & 9,18 & $3,48 \%$ & 6,14 & $3,52 \%$ & 4,46 \\
\hline \% de Bolsa Família & $60,82 \%$ & 22,5 & $58,21 \%$ & 18,36 & $58,22 \%$ & 12,54 \\
\hline \% de Homens & $47,61 \%$ & 24,56 & $48,40 \%$ & 18,76 & $48,46 \%$ & 12,79 \\
\hline \% de Reprovados & $25,46 \%$ & 22,07 & $26,09 \%$ & 17,55 & $26,07 \%$ & 12,87 \\
\hline $\mathbf{N}$ & & 1184 & & 1986 & & 2461 \\
\hline
\end{tabular}

Fonte: Elaborado pelos autores.

No que se refere às estimativas, assim como foi feito na seção anterior, as variáveis de controle foram adicionadas de forma gradual. Além dos seis modelos anteriores, a análise atual conta com mais dois: o modelo 7, que adiciona a distância média da residência do aluno até a escola dos pares, e o modelo 8, que considera, ao mesmo tempo, a influência da distância da residêncida do aluno até a escola que ele estuda e até a escola que os pares frequentam. A Tabela 8 exibe os resultados somente para o modelo 8 , quando todas as variáveis de controle são incluídas. ${ }^{5}$

Assim como o trabalho de Gibbons et al. (2013), o presente estudo não encontrou efeito significativo para as variáveis proporção de deficientes, proporção de homens e de beneficiários de programas sociais para todos os raios de vizinhança. Por outro lado, as evidências indicam que o desempenho escolar é negativamente correlacionado com o percentual de vizinhos repetentes quando a vizinhança é definida como o setor censitário, e o raio, $250 \mathrm{~m}$. Considerando o modelo completo, o aumento de $1 \%$ do percentual de repetentes no raio de vizinhança setor censitário (raio de $250 \mathrm{~m}$ ) está associado a uma redução de 3,42 (4,02) pontos na nota do aluno.

É importante notar que esse efeito dos pares através da parcela de adolescente não são identificados quando a vizinhança correspondente a um raio de $500 \mathrm{~m}$ de distância da residência do aluno, resultado consistente com a suposição de Goux e Maurin (2007) de que há subestimação do efeito vizinhança quando a definição de vizinhança é mais longa. Dada a estrutura

5 Os resultados dos demais modelos estão disponíveis mediante solicitação aos autores. 
adotada e a importância do controle para as características não observáveis de vizinhança, uma menor escala é preferível porque dimunui a possibilidade de mudanças não observáveis na vizinhança (Gibbons et al., 2013).

Tabela 8 Resultados - pares de vizinhos - Modelo 8

\begin{tabular}{|c|c|c|c|c|c|c|c|c|c|c|c|c|}
\hline Variáveis & & \multicolumn{3}{|c|}{ Setor censitário } & \multicolumn{4}{|c|}{ Raio $250 \mathrm{~m}$} & \multicolumn{4}{|c|}{ Raio $500 \mathrm{~m}$} \\
\hline$\%$ de de- & 1,019 & & & & 0,165 & & & & 0,845 & & & \\
\hline ficientes & $(4,019)$ & & & & $(5,408)$ & & & & $(6,703)$ & & & \\
\hline$\%$ de & & $-1,354$ & & & & 0,549 & & & & 1,942 & & \\
\hline homens & & $(1,59)$ & & & & $(1,844)$ & & & & $(2,434)$ & & \\
\hline \% de Bol- & & & 2,818 & & & & 0,551 & & & & 0,0966 & \\
\hline sa Família & & & $(1,74)$ & & & & $(1,696)$ & & & & $(2,567)$ & \\
\hline Repe- & & & & $3,420 * *$ & & & & $022^{* *}$ & & & & $-2,869$ \\
\hline tentes & & & & $(1,71)$ & & & & $(1,916)$ & & & & $(2,282)$ \\
\hline $\mathrm{R}^{2}$ & 0,252 & 0,252 & 0,254 & 0,254 & 0,246 & 0,246 & 0,246 & 0,247 & 0,243 & 0,243 & 0,243 & 0,243 \\
\hline $\mathrm{N}$ & & & & 1184 & & & & 1986 & & & & 2461 \\
\hline
\end{tabular}

Fonte: Elaborado pelos autores.

Nota: (1) Desvios padrão (corrigidos por cluster de escolas) entre parêntesis; (2) ${ }^{* *} p<0,01$, ${ }^{* *} p<0,05$, ${ }^{*} p<0,1$.

\section{Considerações finais}

O presente artigo investigou a associação entre as características da vizinhança e o desempenho escolar na Cidade do Recife, relação ainda pouco explorada no Brasil. O trabalho utilizou da base de dados da Fundaj (2013) para construir as variáveis de vizinhança dos alunos considerando pequenas escalas geográficas e um conjunto abrangente de variáveis de controle para alunos, escolas e famílias. Tais características permitiram avanço empírico sobre o conhecimento disponível na literatura nacional sobre o tema.

A influência da vizinhança foi analisada em dois momentos distintos neste estudo. No primeiro momento, verificou-se que o desempenho escolar em matemática dos alunos do sexto ano das escolas públicas de Recife está positivamente associado à organização territorial da cidade. Os resultados indicam que os alunos residentes em uma vizinhança mais privilegiada tendem apresentar, em média, melhor desempenho em ma- 
temática. Contudo, uma desvantagem dessa perspectiva, além dos problemas de identificação causal e precisa do efeito, é sua incapacidade de apontar mecanismos pelos quais tais efeitos operam.

A segunda análise teve como objetivo investigar se o efeito da vizinhança operaria por meio da influência dos pares dos alunos habitantes da mesma vizinhança. As evidências encontradas sugerem a correlação negativa entre a proporção de repetentes vizinhos e o desempenho de matemática quando se consideram os menores raios de vizinhança.

O conjunto de evidências obtidas no trabalho sugere, pois, que o desempenho escolar dos alunos das escolas públicas da Cidade do Recife pode ser afetado não apenas por características individuais, familiares ou escolares, mas também pelas características de suas vizinhanças e pela influência de seus pares. Note-se que, se o ambiente urbano local importa para o desempenho dos alunos como sugerido pelo trabalho, além do foco da ação pública mais geral na melhoria desse ambiente (melhores condições de infraestrutura urbana, por exemplo), as políticas públicas que intentem a melhoria do desempenho escolar deveriam favorecer a maior permanência na escola e a melhoria de sua qualidade, sobretudo em comunidades em localizações ambientais desfavoráveis.

\section{Referências}

AINSWORTH, J. W. Why does it take a village? The mediation of neighborhood effects on educational achievement. Social Forces, 81(1), 117-152, 2002.

ALVES, F., FRANCO, C., RIBEIRO, L. C. Q. Segregação residencial e desigualdade escolar no Rio de Janeiro. In: RIBEIRO, L. C. Q e KAZTMAN, R. A cidade contra a escola: segregação urbana e desigualdades educacionais em grandes cidades da América Latina. Rio de Janeiro: Letra Capital. 2008

BECKER, K. L.; KASSOUF, A. L. Violência nas escolas públicas brasileiras: uma análise da relação entre o comportamento agressivo dos alunos e o ambiente escolar. Nova Economia, v. 26, n. 2, 2016.

BOLSTER, A. et al. Neighbourhoods, households and income dynamics: A semi-parametric investigation of neighbourhood effects. Journal of Economic Geography, v. 7(1), pp. 1-38, 2007.

CRANE, J. The Epidemic Theory of Guettos and neighborhood Effects on Dropping Out and Teenage Childbearing. American Journal of Sociology. n. 96, pp. 1.126-1.135, 1991.

DING, W.; LEHRER, S. F. Do peers affect student achievement in China's secondary schools?. The Review of Economics and Statistics, v. 89, n. 2, p. 300-312, 2007

DURLAUF, S. Neighborhood effects. Handbook of Regional and Urban Economics. In J. V. Hen- 
derson and J.-F. Thisse (Ed.). Economics, v. 4, 2004.

ESTEVES DE MORAES, A. G.; BELLUZZO JÚNIOR, W. O diferencial de desempenho escolar entre escolas públicas e privadas no Brasil. Nova Economia, v. 24, n. 2, 2014.

FUNDAJ - FUNDAÇÃO JOAQUIM NABUCO. Coordenação de Estudos Econômicos e Populacionais. Acompanhamento Longitudinal do Desempenho Escolar de Alunos da Rede Pública de Ensino Fundamental do Recife. Recife, 2013.

GIBBONS, S.; SILVA, O.; WEINHARDT, F. Everybody needs good neighbours? Evidence from students' outcomes in England. The Economic Journal, v. 123, n. 571, p. 831-874, 2013.

GONÇALVES, M. B. C.; SILVEIRA NETO, R. M. Persistência intergeracional de educação no Brasil: o caso da Região Metropolitana de Recife. Revista de Estudos Econômicos (USP), v. 43, p. $435-463,2013$.

GOUX, D.; MAURIN, E. Close neighbours matter: neighbourhood effects on early performance at school. Economic Journal, v. 117(523), pp. 1.193-2.015, 2007.

INEP. Indicador de adequação da formação do docente da educação básica. Nota Técnica $N^{\circ}$ 020/2014, 2014a. Disponível em: http://download.inep.gov.br/informacoes_estatisticas/ indicadores_educacionais/2014/docente_formacao_legal/nota_tecnica_indicador_docente_formacao_legal.pdf. Acesso em: 5 de nov. 2015.

INEP. Indicador de Esforço Docente. Nota Técnica No 039/2014, 2014b. Disponível em: http://download.inep.gov.br/informacoes_estatisticas/indicadores_educacionais/2014/ docente_esforco/nota_tecnica_indicador_docente_esforco.pdf. Acesso em: 5 de nov. 2015.

INEP. Indicador para mensurar a complexidade da gestão nas escolas a partir dos dados do Censo Escolar da Educação Básica. Nota Técnica Nº 040/2014, 2014c. Disponível em: http://download.inep.gov.br/informacoes_estatisticas/indicadores_educacionais/2014/ escola_complexidade_gestao/nota_tecnica_indicador_escola_complexidade_gestao.pdf. Acesso em: 5 de nov. 2015.

INEP. Indicador de Nível Socioeconômico (Inse) das escolas. Nota técnica s/n, 2015. Disponível em http://download.inep.gov.br/informacoes_estatisticas/indicadores_educacionais/2015/nota_tecnica/nota_tecnica_inep_inse_2015.pdf. Acesso em: 5 de nov. 2015.

JENCKS, C.; MAYER, S. E. The social consequences of growing up in a poor neighborhood. Inner-City Poverty in the United States, v. 111, p. 186, 1990.

LINDAHL, L. A comparison of family and neighborhood effects on grades, test scores, educational attainment and income-evidence from Sweden. The Journal of Economic Inequality, v. 9, n. 2, p. 207-226, 2011.

LUDWIG, J., LADD, H. F., DUNCAN, G. J. Urban Poverty and Educational Outcomes. Brookings-Wharton Pap. Urban Aff. 147-201, 2001.

MANSKI, C. Identification of endogenous social effects: The reflection problem. Review of Economic Studies, v. 60(3), pp. 531-542, 1993.

MENEZES-FILHO, N. Os determinantes do desempenho escolar do Brasil. São Paulo: Instituto Futuro Brasil, 2007.

MENEZES-FILHO, N.; RIBEIRO, F.P. Os determinantes da melhoria do rendimento escolar. In: GIAMBIAGI, F.; HENRIQUES, R.; PESSÔA, S.; VELOSO, F. (Org.). Educação básica no Brasil. Rio de Janeiro: Elsevier, 2009. p. 171-188. 
MOFFITT, R. A. Policy interventions, low-level equilibria, and social interactions. Social Dynamics, v. 4, n. 45-82, p. 6-17, 2001.

OLIVEIRA, T. G.; SILVEIRA NETO, R. M. Segregação residencial na Cidade do Recife: Um estudo da sua configuração. Revista Brasileira de Estudos Regionais e Urbanos, 2016.

RAPOSO, I. P. A, MENEZES, T. A; CARVALHO, R.; NÓBREGA, R. Z. Difusão do efeito dos pares dentro da rede de amizades de sala de aula. In: XIII ENCONTRO NACIONAL DA ASSOCIAÇÃO BRASILEIRA DE ESTUDOS REGIONAIS E URBANOS, 2015. Anais...

RIBEIRO, L. C. de Q.; KOSLINSKI, M. C. Fronteiras Urbanas e Oportunidades Educacionais: o caso do Rio de Janeiro. In: 33ª REUNIÁO ANUAL da ANPOCS, 2009.

SANBONMATSU, L.; KLING, J.; DUNCAN, G.; BROOKS-GUNN, J. Neighborhoods and academic achievement: Results from the moving to opportunity experiment'. Journal of Human Resources, v. 41(4), pp. 649-691, 2006.

SOARES, J. F.; RIGOTTI, J. I. R.; ANDRADE, L. T. As desigualdades socioespaciais e o efeito das escolas públicas de Belo Horizonte. In: RIBEIRO, L. C. Q; KAZTMAN, R. A cidade contra a escola: segregação urbana e desigualdades educacionais em grandes cidades da América Latina. Rio de Janeiro: Letra Capital. 2008

SOLIS, P. Efeitos do nível socioeconômico da vizinhança na continuidade escolar entre o Ensino Médio e o Pré-Universitário no México, Distrito Federal. . In: RIBEIRO, L. C. Q; KAZTMAN, R. A cidade contra a escola: segregação urbana e desigualdades educacionais em grandes cidades da América Latina. Rio de Janeiro: Letra Capital. 2008

TORRES, H; FERREIRA, M.; GOMES, S. Educação e segregação social: explorando o efeito das relações de vizinhança. In: MARQUES, E.; TORRES, H. (Org.). São Paulo: segregação, pobreza e desigualdades sociais. São Paulo: Editora Senac, 2004. p. 123-142.

VASCONCELLOS, I. C.; ROCHA, R. C. B. Interação social e evasão escolar nas favelas do Rio de Janeiro: um problema de identificação. In: XXXIV ENCONTRO NACIONAL DE ECONOMIA 2006. Anais... Disponível em <http://www.anpec.org.br/encontro2006/artigos/A06A090.pdf>. Acesso em: 10 de out. 2016

WILSON, W. J. The truly disadvantaged: The inner city, the underclass and public policy. Chicago. University of Chicago, 1987.

\section{Sobre os autores}

Julia Rocha Araujo - araujorjulia@gmail.com

DEPEC/Universidade Federal do Rio Grande do Norte, Natal, Rio Grande do Norte, Brasil.

ORCID: https://orcid.org/0000-0001-8861-0978.

Raul da Mota Silveira Neto - rau.silveira@uol.com.br

PIMES/Universidade Federal de Pernambuco, Recife, Pernambuco, Brasil.

ORCID: https://orcid.org/0000-0003-0328-4806.

Os autores agradecem à Fundação Joaquim Nabuco e, em especial, às pesquisadoras Isabel Raposo e Michela Camboim por fornecer o acesso aos dados derivados da pesquisa intitulada "Acompanhamento Longitudinal do Desempenho Escolar de Alunos da Rede Pública de Ensino Fundamental do Recife”, realizada no ano de 2013.

\section{Sobre o artigo}

Recebido em 24 de novembro de 2017. Aprovado em 17 de dezembro de 2018. 